\title{
Estrutura Ocupacional, Autoridade Gerencial e Determinação de Salários em Organizações Fordistas: o Caso da Indústria de Transformações no Brasil
}

\author{
Jorge Alexandre Neves \\ Danielle Cireno Fernandes
}

\begin{abstract}
Resumo
Este trabalho analisa o papel que variáveis relacionadas à estrutura ocupacional e de classe exercem no processo de determinação dos salários em organizações fordistas, não apenas de forma direta, mas também como mediadoras da relação entre capital humano e salários. As abordagens funcionalista e crítica são consideradas para formulação das hipóteses de pesquisa. Os testes de hipóteses são realizados através de um modelo linear hierárquico. Ao final, conclui-se que fatores relativos, tanto a estrutura ocupacional quanto de classes, exercem papel relevante no processo de determinação dos salários dos empregados do setor da indústria de transformação no Brasil; contudo evidencia-se que a variável de classe (que separa os empregados entre gerentes/supervisores e trabalhadores operacionais), apresenta maior poder de explicação da determinação de salários em organizações fordistas.
\end{abstract}

Palavras-chaves: autoridade; estrutura ocupacional; posição de classe; determinação de salários; fordismo.

\begin{abstract}
This work analyzes the hole of variables that measures occupational structure and social class in the process of wage determination in fordist organizations, not only in the direct way, but also as mediators of the relationship between human capital and wage. The Functionalist and Critic perspectives are considered as the basis of the research hypotheses formulations. The Hierarchical Linear Model does the hypotheses testing. At the end, one concludes that factors related to the occupational structure and social class function as a relevant hole in the process of wage determination of the manufacturing industry in Brazil. However it is shown that the class variable (which separates employees from managers/supervisors and line workers) shows more explanatory power in wage determination in fordist organization.
\end{abstract}

Key words: authority; occupational structure; class position; earnings determination; fordism. 


\section{INTRODUÇÃO}

Em nosso presente estudo, temos a intenção de observar a validade de algumas das teorias oriundas de diferentes abordagens para a explicação do processo de determinação dos salários, bem como para o estudo da variação da taxa de retorno salarial do investimento em capital humano ${ }^{(1)}$ por parte dos empregados em organizações da indústria de transformação no Brasil. Baseamo-nos em um banco de dados de grande porte, que nos permite realizar análises estatísticas bastante arrojadas. Da mesma forma, utilizamos métodos estatísticos mais avançados do que as funções de salário que tomam como base a análise de regressão de mínimos quadrados ordinários, geralmente utilizadas neste tipo de estudo.

Na próxima seção, vamos expor as diferentes teorias que orientam o trabalho, bem como as hipóteses que delas são derivadas. Posteriormente, serão apresentados alguns detalhes a respeito da base de dados e do modelo estatístico usado para o teste das hipóteses. A seguir, demonstrar-se-ão os resultados e suas implicações. Finalmente, na última parte, serão apresentadas as conclusões finais do trabalho.

\section{Problema de Pesquisa: Posição Gerencial, Autoridade Racional-Burocrática e a Determinação de Salários em Organizações Fordistas}

Poder e autoridade têm sido, já de longa data, conceitos centrais na teoria organizacional (vide Thompson [1969], Prestes Motta [1990], Thompson e McHugh [1990], Pagès et al. [1993], Hall [1996] e Scott [1998], entre outros). Como demonstram alguns autores, em geral os "Cientistas Sociais definem autoridade como poder legítimo" (Scott, 1998, p. 307). Da mesma forma, poder tem sido predominantemente definido a partir do conceito de Max Weber que, segundo Dahrendorf (1982), se define como a probabilidade que um dado ator, mesmo em uma teia de relações sociais, tem de fazer prevalecer a sua vontade, apesar das possíveis resistências dos outros indivíduos. Ou, como proposto por Cartwright (apud Scott, 1998, p. 303): "poder para controlar ou influenciar o outro baseia-se no controle sobre as coisas que ele (o outro) valoriza". No presente estudo, centramos a análise sobre o conceito de autoridade, ou seja, do poder socialmente (seja em uma esfera de grupo informal, organizacional ou macrosocial) legitimado ${ }^{(2)}$. 
Weber (1978) definiu três tipos de autoridade: legal (também denominada por muitos como racional-burocrática), tradicional e carismática. O primeiro tipo ideal se faria predominante nas organizações modernas, em contraste com as outras formas de autoridade, que predominariam nas organizações típicas de sociedades pré-modernas. Segundo Bottomore (1978, p. 94) há na teoria de Weber dois argumentos que são cruciais para a sua análise das organizações modernas:

“o primeiro é que a burocracia, no sentido de uma administração racional e impessoal, baseada na competência técnica e em diplomas educacionais, caminha ao lado da 'democratização' e do nivelamento das diferenças sociais, com o resultado de que as classes sociais deixem de ter grande importância política. O segundo é que os funcionários - os chefes da administração - são os mais óbvios sucessores dos possuidores dos meios de produção como dirigentes da sociedade”.

Na sua visão, portanto, Weber (1978) reservou um lugar privilegiado para os gerentes, administradores e tecnocratas em geral na sociedade moderna. Isto se daria, de acordo com Dahrendorf (1982), porque o capitalismo moderno se caracteriza pela separação entre propriedade e controle dos meios de produção; o segundo fator (o controle) passa a desempenhar o papel central no funcionamento das organizações modernas. A firma moderna não é mais o reino do que ficou conhecido na literatura como o empresário schumpeteriano, o líder visionário que baseia a sua gestão, fundamentalmente, em uma autoridade carismática. Como afirma Gorz (1987, p. 70), na sociedade moderna não há espaço para a empresa tradicional gerida por um empresário schumpeteriano, pois "o próprio poder pessoal do patrão pode ser destruído e, com ele, esse tipo de empresa”. Outras empresas, sem dúvida, tomarão seu lugar, nas quais a dominação do capital terá bases menos frágeis do que a autoridade pessoal do empresário”. Esta autoridade pessoal ou carismática é substituída nas organizações modernas justamente pela autoridade racional-burocrática definida por Weber (1978). Por sua vez, como sugerido por Bottomore (1978) na citação apresentada acima, a autoridade racional-burocrática alimenta-se fortemente da competência técnica e dos diplomas educacionais.

A tradição teórica fundada por Weber (1978), contudo, influenciou posteriormente dois grupos antagônicos de abordagem teórica. De um lado, Parsons (1968) levou a cabo uma interpretação muito original da teoria da modernidade de Weber e fundou o que ficou conhecido como o funcionalismo americano. De outro lado, Dahrendorf (1982) fundou uma tradição acadêmica diferenciada, fazendo uma interpretação crítica da teoria weberiana a partir de um intenso diálogo com a abordagem marxista, dando assim início a um diversificado movimento teórico e intelectual denominado por muitos como neomarxismo e por outros tantos 
como neoweberianismo. Aqui, nos referiremos a estas duas abordagens concorrentes como escola funcionalista e escola crítica.

As teorias funcionalista e crítica serão utilizadas aqui para analisar a influência da estrutura ocupacional e da posição gerencial sobre a determinação de salários em organizações fordistas. A especificação sobre organizações fordistas se faz necessária, pois está na sua típica separação taylorista entre concepção e execução do trabalho, a base do controle gerencial apresentado como de vital importância por Dahrendorf (1982) ${ }^{(3)}$.

Por um lado, a tese funcionalista a respeito do posicionamento dos indivíduos nas hierarquias sócio-economicas das organizações, bem como da sociedade como um todo, tomou de Weber a preocupação com os aspectos relativos a competências técnicas. $\mathrm{O}$ argumento central desta tese pode ser sintetizado na seguinte proposição apresentada por Davis e Moore (1981, p. 127):

“a explicação do motivo pelo qual posições que exigem alta qualificação técnica recebem recompensas bastante elevadas é fácil de ver, pois se trata do mais simples caso de distribuição de recompensas para atrair o talento e motivar o treinamento”.

A abordagem funcionalista levou à teoria da alocação de status $^{(4)}$, que se baseou fortemente na concepção multidimensional de estratificação social de Weber (1978). Os índices de posição sócio-econômica das ocupações foram criados para satisfazer este aspecto multidimensional. Blau e Duncan (1967) foram os criadores do primeiro índice de status sócio-econômico das ocupações, tomando como base as variáveis renda e educação. A fundamentação teórica da teoria da alocação de status é a de que a posição ocupacional do indivíduo é o atributo que melhor resume a dimensão técnica da hierarquização social, tanto em termos macro quanto em nível organizacional. O status ocupacional, portanto, seria o melhor indicador da posição que o indivíduo ocupa nas hierarquias existentes tanto em sociedades quanto em organizações.

Sewell e Hauser (1975) mostraram que a posição ocupacional tem um efeito aditivo em relação aos fatores de capital humano no processo de determinação de salários. Ou seja, uma parte expressiva da variância dos salários poderia ser explicada pelo status ocupacional dos indivíduos, mesmo quando os fatores de capital humano são mantidos constantes. Eles fizeram uso de modelos de análise de trajetória para tentar mostrar que parte do efeito que a escolaridade tem sobre o salário é mediada pela posição ocupacional (efeito indireto). Da mesma forma, Haller e Spenner (1977) mostraram que a relação entre fatores de capital humano e renda varia de acordo com a ocupação do indivíduo; portanto, para a teoria 
da alocação de status, a posição ocupacional não apenas teria um efeito direto e independente sobre os salários dos indivíduos, como também interferiria na forma pela qual a escolaridade influencia os salários. Mais especificamente, a expectativa é a de que não somente os salários sofram aumentos com a elevação do status ocupacional, como também que o efeito da escolaridade aumente com a elevação do nível ocupacional.

Por outro lado, a abordagem crítica vê a posição de gerência como sendo fundamentalmente baseada na habilidade de impor a disciplina organizacional sobre os trabalhadores operacionais (Gee et al., 1996). Seguindo a tradição inaugurada por Dahrendorf (1982), a chamada análise de classes (Wright e Perrone, 1977; Singer, 1981) enquadra-se na abordagem crítica e tem produzido importantes contribuições para a compreensão da determinação das posições hierárquicas e dos salários. Wright e Perrone (1977) afirmam que a abordagem marxista tradicional de unidade do proletariado, não consegue explicar as complexas relações sociais existentes no interior das empresas capitalistas. Eles sugerem, então, que as pessoas que se incluem na categoria de empregados, na verdade compõem duas (e não apenas uma) classes: gerentes/administradores e trabalhadores/operários. A primeira reúne os empregados em nível de supervisão e gerência (aqueles que têm outros empregados que lhes são subalternos). A segunda reúne os empregados que trabalham no nível operacional e que não têm quaisquer outros empregados como subalternos; portanto, para eles, a aplicação do conceito de status ocupacional não esgota o problema da posição hierárquica dos empregados nas organizações capitalistas de produção.

Wright e Perrone (1977) afirmam que, mesmo mantendo-se constante os fatores de capital humano e a posição ocupacional dos empregados, ainda assim observa-se que aqueles que estão em uma posição gerencial percebem salários mais elevados do que os operários. Da mesma forma, eles sugerem que não há apenas esse efeito direto e independente da posição de classe sobre o salário, mas também que o efeito da escolaridade sobre os rendimentos dos empregados do nível gerencial é maior do que dos operários. Tal efeito se daria em função de que gerentes e supervisores desempenham papel relevante na imposição da autoridade da empresa e dos mecanismos de exploração do trabalho. Desta forma, a escolaridade teria maior valor e utilidade para empregados do nível gerencial, pois estes se beneficiariam sobremaneira de níveis educacionais mais elevados, em função de que reforçam a sua autoridade. Ou seja, a escolaridade, para a visão crítica, desempenha papel central na determinação dos salários, não por razões técnicas, mas por motivos, digamos, políticos, ou seja, porque reforçam a autoridade dos gerentes e supervisores sobre os trabalhadores operacionais.

As teorias discutidas acima servirão de base para que possamos definir nossas 
hipóteses de pesquisa. Assim sendo, podemos resumir nossas hipóteses de pesquisa da seguinte forma:

. Hipótese 1: Baseados na abordagem funcionalista, podemos esperar que, mesmo mantendo-se constante os fatores de capital humano, a elevação do status ocupacional gera aumento do salário.

- Hipótese 2: Baseados na abordagem funcionalista, podemos afirmar que o efeito da escolaridade sobre o salário aumenta com a elevação do status ocupacional.

- Hipótese 3: Baseados na abordagem crítica, podemos esperar que, mesmo mantendo-se constante os fatores de capital humano e status ocupacional, empregados do nível gerencial recebem salários mais altos do que os operários.

. Hipótese 4: Baseados na abordagem crítica, podemos afirmar que o efeito da escolaridade sobre o salário é maior para gerentes e supervisores do que para os operários.

\section{Metodologia}

\section{Dados}

Os dados para o teste das hipóteses de pesquisa apresentadas acima vêm da Pesquisa Nacional por Amostra de Domicílios (PNAD) de 1988. Os microdados da PNAD-88 originam-se de uma amostra estratificada por conglomerados selecionados em estágios múltiplos. Ela tem mais de 290.000 observações e enfoca, particularmente, as áreas relativas a mercado de trabalho, estratificação e mobilidade social. Aqui utilizamos uma subamostra com 7.978 casos de empregados do setor da indústria de transformação no Brasil como um todo, que apresentaram dados para todas as variáveis necessárias à nossa análise.

\section{Modelo e Variáveis}

Nossas hipóteses de pesquisa serão testadas a partir de um modelo linear hierárquico com dois níveis ${ }^{(5)}$. No primeiro nível hierárquico será estimado o logaritmo neperiano (ln) dos salários dos empregados a partir de um vetor de variáveis independentes que inclui: (1) as variáveis de capital humano: escolaridade (medida em anos de educação bem sucedidos), experiência (em anos de experiência de trabalho), experiência ao quadrado, migração (migrou = 1); e (2) sexo (masculino =1). No segundo nível hierárquico, serão estimados o intercepto e o coe- 
ficiente de regressão da escolaridade-lnsalário, a partir de duas variáveis independentes: status ocupacional ${ }^{(6)}$ e posição de classe (nível de gerência e supervisão = 1). O modelo estimado pode ser resumido da seguinte forma:

$$
\begin{aligned}
& \operatorname{lnSalário}=\beta_{0 \mathrm{j}}+\beta_{1 \mathrm{j}}(\text { Escolaridade })+\beta_{2 \mathrm{j}}(\text { Experiência })+\beta_{3 \mathrm{j}}\left(\text { Experiência }^{2}\right)+ \\
& \beta_{4 j}(\text { Migração })+\beta_{5 j}(\text { Sexo })+r_{i j} \\
& \beta_{0 \mathrm{j}}=\gamma_{00}+\gamma_{01} \text { (Posição de Classe) }+\gamma_{02} \text { (Status Ocupacional) }+\mathrm{u}_{\mathrm{oj}} \\
& \beta_{1 j}=\gamma_{10}+\gamma_{11} \text { (Posição de Classe) }+\gamma_{12} \text { (Status Ocupacional) }+u_{1 j}
\end{aligned}
$$

O modelo linear hierárquico apresenta a grande vantagem, para aqueles que trabalham com dados hierárquicos, de evitar a violação de pressupostos excessivamente rígidos relativos à análise de regressão de mínimos quadrados ordinários (vide Bryk e Raundenbush, 1992). Em particular, a análise de regressão de mínimos quadrados ordinários exige que as observações sejam independentes. Tal pressuposto é muitas vezes violado, quando se tem dados com diferentes níveis hierárquicos. No presente estudo, por exemplo, pessoas de mesmo grupo ocupacional ou de mesma posição de classe têm algo em comum que as diferencia do restante dos indivíduos. Tal característica faz com que indivíduos de um mesmo grupo ocupacional ou classe representem observações que são dependentes entre si. A utilização de um modelo linear hierárquico, portanto, eleva a confiabilidade dos nossos resultados, quando comparados com a estimação de funções de salários a partir de modelos de regressão de mínimos quadrados ordinários.

\section{Resultados e Análise}

A Tabela 1, a seguir, apresenta os resultados dos coeficientes do segundo nível hierárquico do nosso modelo apresentado acima ${ }^{(7)}$. Vemos que o status ocupacional tem efeito altamente significativo sobre o salário médio $\left(\gamma_{02}=0,040069\right.$ e $\mathrm{p}<0,001$ ), porém não apresenta qualquer influência sobre o coeficiente de regressão da escolaridade $\left(\gamma_{12}=-0,000052\right.$ e $\left.\mathrm{p}=0,947\right)$. Posição de classe tem um efeito significativo tanto sobre o nível salarial médio $\left(\gamma_{01}=0,286675 \text { e } \mathrm{p}=0,016\right)^{(8)}$, quanto sobre o coeficiente de regressão da escolaridade $\left(\gamma_{11}=0,049495\right)$. Isto nos indica que, de fato, três das nossas hipóteses de pesquisa obtiveram suporte empírico. Podemos comentar os resultados relativamente às hipóteses da seguinte forma.

- Como vários outros estudos já haviam indicado, o status ocupacional tem efeito extremamente significativo sobre o nível de salário das pessoas. Este efeito direto é independente de qualquer outro fator e se manifesta quando se man- 
têm sobre controle tanto fatores de capital humano quanto a variável posição de classe. Vemos, portanto, que parte da variação dos salários não se deve a atributos individuais de capital humano, mas a estruturas de cargos e ocupações das empresas. Tal resultado indica que há certa rigidez de salários, associada a fatores organizacionais, como as estruturas ocupacionais. Indica também que, muito provavelmente, parte da produtividade dos empregados está associada ao cargo que estes ocupam, não apenas a atributos pessoais. Em outras palavras, o mesmo indivíduo, em cargos diferentes, alcançará níveis distintos de produtividade.

. Da mesma forma, posição de classe também demonstra ter um efeito direto sobre o nível médio de salários, mesmo quando se mantêm sob controle as variáveis de capital humano e o status ocupacional, ou seja, parte da recompensa do trabalho está associada a algo que não é nem atributo individual de qualificação nem nível ocupacional, nos termos tradicionais. Wright e Perrone (1977) argumentam que tal efeito deve observar-se em função de que empregados em nível gerencial desempenham a função de ferramentas para o exercício da autoridade da empresa, bem como tornam possível a exploração do trabalho dos operários, sendo então recompensados por desempenharem tais papéis, ou seja, a posição contraditória de classe de gerentes e supervisores coloca-os em posição de forte tensão, sendo esta, pois, reconhecida pela direção das empresas, levando a um nível mais elevado de remuneração. Uma coisa, portanto, é um técnico que desempenha uma função operacional; outra é um técnico, com o mesmo nível de qualificação e ocupação, que desempenha atividade de supervisão ou gerência. O primeiro é responsável apenas pelo seu próprio trabalho, ao passo que o segundo se responsabiliza pelo desempenho de outros empregados.

. Embora o status ocupacional tenha forte efeito sobre o nível médio de salário, não parece ter nenhuma influência sobre a forma pela qual escolaridade e salário se relacionam. Isto demonstra que, quando se mantém sob controle a posição de classe, o retorno salarial do investimento em educação dos empregados não parece aumentar com a elevação do nível ocupacional. Tal resultado indica que a hipótese 2 não encontra nenhum suporte empírico da nossa análise; contudo a hipótese 4, pelo contrário, obtém apoio nos resultados apresentados na Tabela 1. De fato, a posição de classe parece exercer influência muito relevante no efeito que a escolaridade tem sobre o salário. Nossos resultados indicam que empregados do nível gerencial têm uma taxa de retorno para cada ano adicional de educação 5,07\% ${ }^{(9)}$ maior que trabalhadores do nível operacional. Tal resultado é coerente com a expectativa de Wright e Perrone (1977) de que a escolaridade serve duplamente ao empregado do nível gerencial, pois este se beneficia dela não apenas porque ela melhora o seu desempenho no trabalho, mas também porque reforça a sua posição de autoridade. 
Tabela 1: Resultados dos Coeficientes do Modelo Linear Hierárquico de Segundo Nível para o Intercepto e o Coeficiente de Regressão da Escolaridade-InSalário como Variáveis Dependentes - Brasil, 1988

\begin{tabular}{|c|c|c|c|c|}
\hline Efeitos Fixos & Coeficiente & Erro Padrão & $\mathbf{t}$ & $\mathbf{p}$ \\
\hline \multicolumn{5}{|l|}{ Modelo para o Salário Médio $\left(\beta_{0 \mathrm{j}}\right)$} \\
\hline Intercepto, $\gamma_{00}$ & 6,597596 & 0,051375 & 128,420 & 0,000 \\
\hline Posição de Classe (Nível Gerencial = 1), $\gamma_{01}$ & 0,286675 & 0,119213 & 2,405 & 0,016 \\
\hline Status Ocupacional, $\gamma_{02}$ & 0,040069 & 0,003425 & 11,699 & 0,000 \\
\hline \multicolumn{5}{|l|}{$\begin{array}{l}\text { Modelo para o Coeficiente de Regressão } \\
\text { da Escolaridade-InSalário }\left(\beta_{1 j}\right)\end{array}$} \\
\hline Intercepto, $\gamma_{10}$ & 0,077224 & 0,009536 & 8,098 & 0,000 \\
\hline Posição de Classe (Nível Gerencial = 1), $\gamma_{11}$ & 0,049495 & 0,017411 & 2,843 & 0,005 \\
\hline Status Ocupacional, $\gamma_{12}$ & $-0,000052$ & 0,000774 & $-0,067$ & 0,947 \\
\hline
\end{tabular}

Fonte: PNAD-88.

Quanto à hipótese 4 há, entretanto, um ponto que precisa ser ressaltado. Nossa análise estatística demonstrou que, de fato - no caso dos empregados da indústria de transformação no Brasil - gerentes e supervisores desfrutam de maior taxa de retorno salarial para seus investimentos em educação. Tal resultado representa um reforço da aceitação da adequabilidade da análise de classe para o estudo da autoridade gerencial em organizações modernas (Marques, 1998).

Outra explicação teórica possível para o resultado aqui observado (relativo à hipótese 4), como a apresentada por Welch (1970), baseia-se no argumento de que a escolaridade tem dois efeitos diferentes sobre o salário. O primeiro é o efeito direto. Neste, é a elevação do nível educacional do empregado que aumenta a sua produtividade e, conseqüentemente, o seu salário. O segundo é o efeito indireto. Este só existiria para aqueles que se encontram em posição de tomada de decisões. O aumento da escolaridade de um indivíduo que desempenha uma função na qual tem de fazer escolhas de significativa relevância para a empresa melhoraria a qualidade de suas decisões, elevando a sua remuneração. Empregados no nível gerencial sofreriam, portanto, ambos os efeitos da educação sobre o salário: eles ficariam mais produtivos enquanto trabalhadores, bem como se tornariam melhores tomadores de decisão. Os trabalhadores do nível operacional sofreriam apenas o efeito direto da educação.

A possível explicação exposta acima, contudo, não é compatível com a confirmação da hipótese 2. Dentro da abordagem teórica do efeito alocativo do capital humano proposta por Welch (1970), não haveria explicação para um maior efeito 
direto da escolaridade sobre o salário de empregados da classe de gerentes/ supervisores do que daqueles da classe de trabalhadores/operários. Desta forma, podemos concluir que a abordagem crítica da análise de classes é a que obtém, sem dúvida, o maior suporte empírico da análise aqui desenvolvida.

\section{Conclusão}

O estudo do processo de determinação de salários tem sido dominado pela abordagem neoclássica da economia. A teoria do capital humano forneceu algumas das primeiras análises acerca dos fatores explicativos da variação de salários. Embora tais fatores tenham continuadamente provado a sua relevância, outros estudos têm demonstrado que a realidade é mais complexa do que o modelo proposto pelos economistas neoclássicos. Fatores organizacionais e institucionais, em diversos estudos, têm mostrado desempenhar importante papel causal na determinação de salários. Em nosso estudo, embora mais uma vez reconhecendo a importância dos fatores de capital humano, mostramos também que a estrutura ocupacional e a posição de classe (base da autoridade gerencial) são de evidente relevância para a explicação do processo de formação de salários.

Outros estudos (Haller, 1981; Neves, 1997) já haviam ressaltado este caráter multicausal do salário e da renda. O reconhecimento desta realidade é de grande relevância, tanto teórica quanto prática. Do lado prático, ao assumir-se que fatores estruturais (sejam eles organizacionais, institucionais ou macrossociais) desempenham papel importante na determinação dos salários, cumpre reconhecer que a maior parte das políticas de trabalho hoje em voga são insuficientes para resolver alguns dos grandes problemas atuais (desemprego, baixos salários etc.), pois buscam apenas interferir no nível de qualificação da mão-de-obra. Do lado teórico, o estudo produziu fortes evidências empíricas de que o papel desempenhado por gerentes e supervisores, como instrumentos de aplicação da autoridade organizacional, é de enorme relevância para a compreensão da determinação de salários. Em outras palavras, não apenas a posição de classe tem efeito líquido (independente dos fatores de capital humano e da posição organizacional) sobre o salário, como também desempenha importante papel de mediador entre escolaridade e salário, ou seja, organizações fordistas premiam através de maiores salários preferencialmente os empregados que se encontram em posição hierarquicamente superior em termos políticos e não técnicos.

Finalmente, deve-se ressaltar que o nosso estudo aplicou uma metodologia estatística (modelo linear hierárquico) mais avançada do que a normalmente utiliza- 
da para a análise da determinação de salários. Neste sentido, portanto, o nosso trabalho representa um avanço, porquanto, ao utilizar um modelo que evita o pressuposto da independência total das observações, produz resultados mais confiáveis.

\section{Notas}

${ }^{1}$ Embora a teoria apresente inúmeros fatores relevantes de capital humano, apenas três serão aqui considerados para a nossa análise: escolaridade, experiência de trabalho e migração. O primeiro representa, sem dúvida, o principal fator de capital humano. O segundo representa uma proxy para o chamado on the job training. Finalmente, o terceiro é comumente utilizado em análises sobre o efeito do capital humano, pois representa, entre outras coisas, uma proxy para o nível de ambição dos indivíduos. Escolaridade será a única a ser aplicada como variável de teste no presente estudo. Os outros dois fatores representarão apenas variáveis de teste.

${ }^{2}$ Não é nossa intenção, contudo, centrar a nossa análise em aspectos culturais da autoridade, como enfatizado por Davel e Vasconcelos (1997).

${ }^{3}$ Não pretendemos entrar aqui em uma discussão mais detalhada a respeito do exercício da autoridade gerencial em organizações chamadas pós-fordistas. Acreditamos apenas que a escolha de um banco de dados de indivíduos formalmente empregados na indústria de transformação no Brasil em 1988, garante-nos que se trata aqui de pessoas com vínculo empregatício com organizações tipicamente fordistas.

${ }^{4}$ Sobre a importância dos sistemas de status para as organizações, ver Thompson (1969).

${ }^{5}$ Sobre os modelos lineares hierárquicos, ver Bryk e Raundenbush (1992).

${ }^{6}$ A variável status ocupacional foi construída a partir do índice de ocupações de Valle Silva (1985), que toma como base a metodologia desenvolvida por Blau e Duncan (1967).

${ }^{7}$ Os resultados relativos ao primeiro nível hierárquico foram: $\beta_{1 \mathrm{j}}=0,09014 ; \beta_{2 \mathrm{j}}=0,01060 ; \beta_{3 \mathrm{j}}=$ $-0,00017 ; \beta_{4 j}=0,14651 ; \beta_{5 j}=0,31145$.

${ }^{8}$ Deve-se ressaltar, contudo, que este coeficiente não é significativo em nível de 0,01 . Isto é relevante pelo fato de que a PNAD-88 é amostra estratificada e por conglomerados. Este tipo de amostragem - como alguns pesquisadores têm ressaltado (Mare, 1980; Hasenbalg e Valle Silva, 1991) - tende a produzir resultados que subestimam o erro padrão dos estimadores.

${ }^{9}$ Tal resultado é encontrado a partir da fórmula: $\operatorname{Exp}\left(\gamma_{11}\right)-1$ X 100. 
ReferênCIAS Bibliográficas

BLAU, P.;

DUNCAN, O.

The american occupational structure. New York: John Wiley \& Sons, 1967.

BOTTOMORE, T.

As classes na sociedade moderna. Rio de Janeiro: Zahar, 1978.

BRYK, A.;

RAUNDENBUSH, S.

Hierarchical linear models. London: Sage Publications, 1992.

CARTWRIGHT, D.

Influence, leadership, control. In: MARCH, J. (Org.). Handbook of organizations. Chicago: Rand McNally, 1965.

DAHRENDORF, R.

As classes e seus conflitos na sociedade industrial. Brasília:

Editora Universidade de Brasília, 1982.

DAVEL, E.;

VASCONCELOS, J.

Gerência e autoridade nas empresas brasileiras: uma reflexão histórica e empírica sobre a dimensão paterna nas relações de trabalho. In: PRESTES MOTTA, F. C.; CALDAS, M. P. (Org.). Cultura organizacional e cultura brasi-

leira. São Paulo: Atlas, 1997.

DAVIS, K.;

MOORE, W.

Alguns princípios de estratificação. In: VELHO, O.; PALMEIRA, M. (Orgs.). Classes e estratificação social. Rio de Janeiro: Zahar, 1981.

GEE, J. et al.

The new work order: behind the language of the new capitalism. Boulder, CO: Westview Press, 1996.

GORZ, A.

Adeus ao proletariado: para além do socialismo. Rio de Janeiro: Forense-Universitária, 1987.

HALL, R.

Organizations: structures, processes, and outcomes. Englewood Cliffs, NJ: PrenticeHall, 1996.

HALLER, A.

Antecedents of income differences: complementary hypotheses from conflicting theories? Research Committee on Social Stratification, International Sociological Association, Paris, Apr. 1981. 
HALLER, A.;

SPENNER, K.

Occupational

income

differentiation in status attainment.

Rural Sociology, v. 42, p. 517-

535, 1977.

HASENBALG, C.;

VALLE SILVA, N.

Raça e oportunidades educacionais no Brasil. In: LOVELL, P.

(Org.). Desigualdade racial no Brasil contemporâneo. Belo Horizonte: UFMG/CEDEPLAR, 1991.

MARE, R.

Social background and school continuation decisions. Journal of the American Statistical Association, v. 75, p. 295-305, 1980.

MARQUES, A.

Condições de trabalho e identidade de classe de profissionais e gerentes brasileiros. Ensaios de Administração, n. 8, 1998.

NEVES, J.

Human capital, social classes, and the earnings determination process in Brazilian agriculture: 1973, 1982, and 1988. Madison, 1997. Thesis (Ph.D. in Sociology) - University of Wisconsin-Madison.

PAGÈS, $M$ et al.

$O$ poder das organizações. São Paulo: Atlas, 1993.
PARSONS, T.

The structure of social action. New York: The Free Press, 1968.

PIORE, M.

The dual labor market: theory and implications. In: GRUSKY, D. (Org.). Social stratification: class, race, and gender in sociological perspective. Boulder, CO: Westview Press, 1994.

PRESTES MOTTA, F. C.

Organização e poder: empresa, estado e escola. São Paulo: Atlas, 1990.

SCOTT, W.

Organizations: rational, natural, and open systems. Englewood Cliffs, NJ: Prentice-Hall, 1998.

SEWELL, W.;

HAUSER, R.

Education, occupation, and earnings: achievements in the early carrier. New York: Academic Press, 1975.

SINGER, $\mathrm{P}$.

Dominação e desigualdade: estrutura de classes e repartição da renda no Brasil. Rio de Janeiro: Paz e Terra, 1981.

THOMPSON, P.;

MCHUGH, D.

Work organizations: a critical introduction. London: MacMillan, 1990. 
THOMPSON, V.

Modern organization. New

York: Alfred A. Knopf, 1969.

THUROW, L.

Education and economic equality. In: KARABEL, J.; HALSEY, A. (Orgs.). Power and ideology in education. New York: Oxford University Press, 1977.

VALLE SILVA, N.

Atualização da escala sócioeconômica das ocupações para 1980. Rio de Janeiro: LNCC, 1985.
WEBER, M.

Economy and society. Berkeley: University of California Press, 1978.

WELCH, F.

Education and production. Journal of Political Economy, v. 78, n. 1, p. 35-59, 1970.

WRIGHT, E.; PERRONE, L.

Marxist class categories and income inequality. American Sociological Review, v. 42, p. 3255, 1977. 